\title{
Reduction of the Poggendorff effect by the motion of oblique lines
}

\author{
TERUNORI MORI \\ Electrotechnical Laboratory, 1-I-4 Umezono, Sakura-mura, Niihari-gun, Ibaraki-ken, Japan
}

\begin{abstract}
The magnitude of the Poggendorff illusion was measured when the test lines were moved up or down and tracked by subjects. The difference between test lines and inducing lines caused by motion of the test lines significantly reduced the magnitude of illusion $(60 \%)$. Supplementary experiments seemed to indicate that location of test lines, perceptual shrinkage of space in the vertical dimension, and effective display time were not the main factors contributing to the reduction in illusion magnitude. Instead, it seems that some reduction in interaction between test and inducing lines was the main cause of the reduction. The rising curve of the reduction was very steep with velocity, and the reduction magnitude was almost constant over most of the range of velocities studied. The current evidence seems to suggest that moving and stationary figures are processed by separate channels and that, therefore, the interaction between them is reduced.
\end{abstract}

Visual-geometric illusions derive from some interaction between test and inducing figures. Illusion magnitude has usually been measured under conditions in which both test and inducing figures are stationary.

The question addressed in the present study was whether or not the interactions that occur would be of the same size when some parts of the figure were in motion and other parts were stationary. Assuming that the interactions are affected by this differential motion, would the illusion become smaller or larger? How much would it change? Would the magnitude of change depend on velocity?

The present experiments were planned to answer these questions. The Poggendorff illusion was selected as a stimulus. The illusion magnitude was measured under conditions in which the test figure (the transverse lines) was moved vertically while the subject tracked it. The vertical parallels remained stationary. Tracking of the test figure was introduced to avoid any perceptual distortion of the test figure, such as shrinkage in the vertical dimension, and to keep both test and inducing figures as clear as possible.

\section{EXPERIMENT 1}

\section{Method \\ Apparatus. A Megraphic 5000 display monitor (P40 phosphor) controlled by a NOVA-3 minicomputer was used in Experiment 1. The display was viewed in a darkened room. The subject was seated $62 \mathrm{~cm}$ from a screen, with his head upright and his chin in a chinrest. \\ Figure 1 shows the figure used in Experiment 1. Vertical line segments EF and $\mathrm{GH}$ were $31 \mathrm{~cm}(28.1 \mathrm{deg})$ in length. Oblique \\ The equipment used in Experiments 2 to 6 was provided in Sydney by ARGC Grant A 74/15177 to P. Wenderoth and H. Beh.}

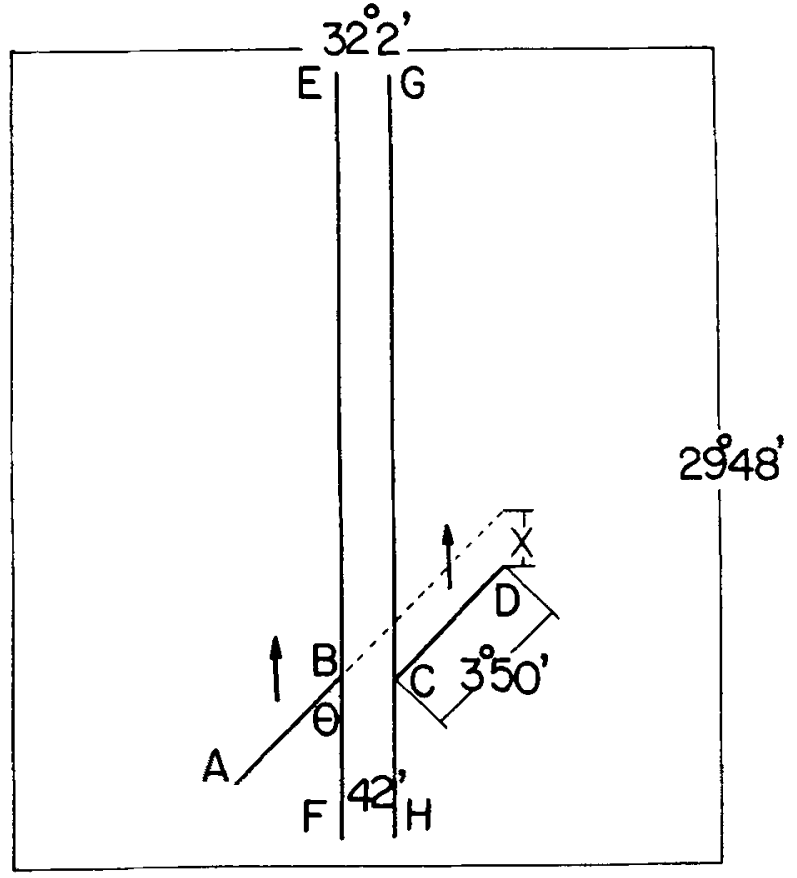

Figure 1. Stimuli used in Experiment 1. The oblique lines $A B$ and $C D$ moved vertically at the rate of .2 or 20.0 deg of visual angle per second. The line segment $\mathrm{CD}$ deviated randomly from true alignment either upward or downward $(X)$. The screen was $35.6 \mathrm{~cm}$ wide and $33.0 \mathrm{~cm}$ high. The test lines $A B$ and $C D$ both abutted the inducing lines EF and GH at an angle $\theta$, in this case $45 \mathrm{deg}$.

line segments $A B$ and $C D$ were $4.13 \mathrm{~cm}(3.8 \mathrm{deg})$ in length. The width between EF and $\mathrm{GH}$ was $.76 \mathrm{~cm}(.7 \mathrm{deg})$. All line widths were $.3 \mathrm{~mm}(.03 \mathrm{deg})$. The angle between the obliques and parallels was $45 \mathrm{deg}$. The screen was $35.6 \mathrm{~cm}$ wide and $33.0 \mathrm{~cm}$ high. All lines had a luminance of $1 \mathrm{~mL}$. The luminance of the background screen was not measurable using a Tektronix $\mathbf{} 16$ digital photometer, but was less than $.01 \mathrm{~mL}$, the lower limit of the photom- 

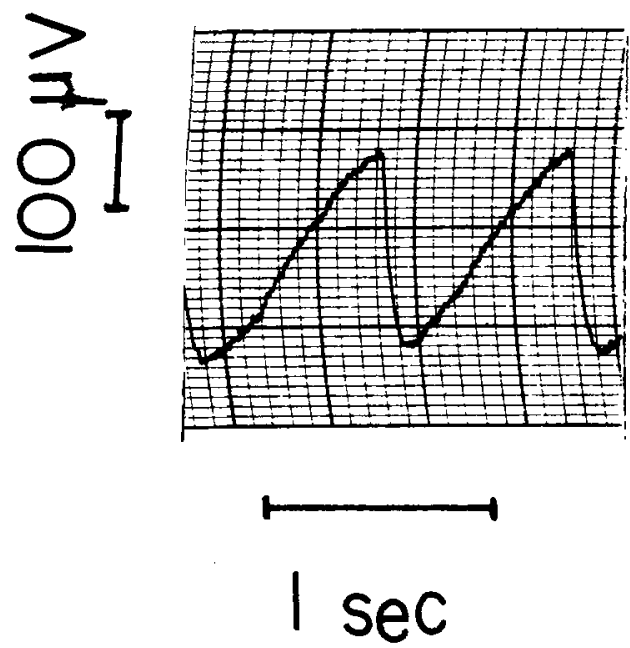

Figure 2. An example of an eye-movement record.

eter. Thus, contrast, defined as $\left(L_{\max }-L_{\min }\right) /\left(L_{\max }+L_{\min }\right)$, exceeded .98.

Procedure. The oblique lines AB and CD moved vertically upward at the rate of either .2 or 20.0 deg of visual angle per second. The subjects were requested to track the oblique lines $\mathrm{AB}$ and $\mathrm{CD}$ smoothly. Eye movement was monitored by electrooculography (EOG). Figure 2 shows an example of eye movements. The subjects judged whether $A B$ and $C D$ were collinear. They pushed key 1 when they judged $A B$ and $C D$ collinear and key 2 otherwise. The misalignment was constant during each presentation. The position of line segment $C D$ was changed randomly after each trial. This was done 50 times and the mean value (alighment error) of the misalignments was calculated for the trials in which key 1 was pushed. The velocity of the oblique lines was alternated randomly between the rates .2 and 20.0 deg of visual angle per second.

Subjects. Six volunteers were used. Five of them were unaware of the purpose of the experiment. All had normal vision.

\section{Results}

The mean value of alignment error at the rate of $.2 \mathrm{deg}$ of visual angle per second, $\mathrm{M1}$, was $1.68 \mathrm{~mm}$, and the standard deviation (SD) was $.24 \mathrm{~mm}$. The mean value of alignment error at the rate of $20.0 \mathrm{deg}$ of visual angle per second, $\mathrm{M} 2$, was $.85 \mathrm{~mm}$, and the SD was $.23 \mathrm{~mm}$. M2 was significantly different from M1 $[t(5)=5.56, p<.005]$. This shows that the Poggendorff illusion was significantly reduced when the oblique lines moved vertically rapidly and the subject's eyes tracked them smoothly and that rapid movement resulted in smaller illusion.

These results raised a number of questions:

(1) Would the size of the reduction be the same when a number of subjects were tested? Would the size of the reduction be the same when the test lines were moved inversely, that is, downward?

(2) Although subjects were instructed to judge when the obliques were roughly at the center of parallels, would these judgments vary because the test lines moved rapidly, and would the magnitude of the Poggendorff illusion depend on the judged location of the obliques?
(3) It is possible that visual space shrinks in the vertical dimension when tracking the vertically moving test lines (Ansbacher, 1944; Cohen, 1967). Such a shrinkage of space in the vertical dimension would perceptually reduce the angle of the test lines and consequently enlarge an acute angle between test and inducing lines. The magnitude of the Poggendorff illusion reduces with the angle (e.g., Cameron \& Steele, 1905). Therefore, although it seems likely that the shrinkage of space in the vertical dimension would be quite small, because the test lines were smoothly tracked by subjects, would that have some effect on the size of the Poggendorff illusion?

(4) The effective display time was shorter in the $20 \mathrm{deg} / \mathrm{sec}$ condition than in the $.2 \mathrm{deg} / \mathrm{sec}$ condition. Was reduction of the illusion in the $20 \mathrm{deg} / \mathrm{sec}$ condition due to the shorter display time?

(5) Exactly how does the illusion magnitude change with the velocity of the oblique lines? Is rapid motion of the oblique lines necessary for a significant reduction of the Poggendorff illusion?

The following experiments were undertaken to answer these questions. Eighty-eight undergraduate and graduate volunteers were assigned randomly to one of Experiments 2, 3,5 and 6. Eight who had served either in Experiment 2 or Experiment 3 also served in Experiment 4.

\section{EXPERIMENT 2}

In order to see clearly a reduction of the Poggendorff illusion, the gap between the parallels was widened from $.76 \mathrm{~cm}(.7 \mathrm{deg})$ to $3.0 \mathrm{~cm}(3.2 \mathrm{deg})$. This experiment was planned to confirm the results of Experiment 1 under different conditions, such as an enlarged gap, different equipment, reversed direction of motion, and a different technique of measurement.

\section{Method}

Apparatus. A PDP-8 computer was used to produce a visual display on a HP1370 display monitor (P4 phosphor). The display was viewed in the dark. The observer was seated $500 \mathrm{~mm}$ from the display, with his head upright and eyes level with the display. The test lines $A B$ and $C D$ in Figure 1 were $4 \mathrm{~cm}(4.3 \mathrm{deg})$ long and were always oriented at $45 \mathrm{deg}$. The inducing lines EF and GH were $20 \mathrm{~cm}(21.2 \mathrm{deg})$ long and were vertical.

Procedure. Each subject completed two conditions: a control, in which the oblique lines were stationary, and an experimental condition, in which the subject tracked the obliques, which moved at a rate of $21.2 \mathrm{deg}$ of visual angle per second either upward or downward. The order of the two conditions was changed randomly. On each trial, the observer judged whether oblique line $\mathrm{CD}$ appeared above or below the left oblique line's extension. Thus, a subjective alignment error was measured using a double, randomly interleaved staircase technique (e.g., Cornsweet, 1962; Wetherill \& Levitt, 1965).

Subjects. Twenty volunteers were selected randomly from among 88 subjects. Ten of them were tested with upward motion and the other 10 were tested with downward motion. 
Table 1

Reduction Magnitude by Motion of Obliques

\begin{tabular}{|c|c|c|c|c|c|c|c|}
\hline & \multicolumn{2}{|c|}{$\begin{array}{c}\text { M1 (in Millimeters) } \\
\text { (Stationary) }\end{array}$} & \multicolumn{2}{|c|}{$\begin{array}{c}\text { M2 (in Millimeters) } \\
\text { (Moving) }\end{array}$} & \multirow{2}{*}{$\begin{array}{l}\text { Reduction } \\
\text { (in Percent) }\end{array}$} & \multirow[b]{2}{*}{$t(9)$} & \multirow[b]{2}{*}{$\mathrm{p}$} \\
\hline & Mean & SD & Mean & SD & & & \\
\hline Experiment 1 & 1.68 & .24 & .85 & .23 & 49 & 5.56 & $<.005$ \\
\hline \multicolumn{8}{|l|}{ Experiment 2} \\
\hline Upward & 9.30 & 3.67 & 3.70 & 3.23 & 60 & 3.04 & $<.002$ \\
\hline Downward & 8.30 & 2.40 & 3.20 & 1.58 & 61 & 4.69 & $<.001$ \\
\hline
\end{tabular}

Note-The velocity for MI in Experiment 1 was very low but not zero $(.2 \mathrm{deg} / \mathrm{sec})$. The number of subjects in Experiment 1 was six.

\section{Results}

The mean value, M1, of the stationary control condition for upward motion was $9.3 \mathrm{~mm}$ and the SD was $3.67 \mathrm{~mm}$. The mean value, M2, of the experimental condition for upward motion was $3.7 \mathrm{~mm}$ and the SD was $3.23 \mathrm{~mm}$. M2 was significantly different from $M 1[t(9)=3.035, p<.02]$.

The mean value, $\mathrm{Ml}^{\prime}$, of the stationary control condition for downward motion was $8.3 \mathrm{~mm}$ and the $\mathrm{SD}$ was $2.40 \mathrm{~mm}$. The mean value, $\mathrm{M} 2^{\prime}$, of the experimental condition for downward motion was $3.2 \mathrm{~mm}$ and the SD was $1.58 \mathrm{~mm}$. M2' was also significantly different from $M 1^{\prime}$ [ $t(9)=4.69, \mathrm{p}<.001$ ]

Thus, the results of Experiment 1 were confirmed under different conditions. The results of Experiments 1 and 2 are shown in Table 1.

The reduction with upward motion was about $60 \%$, and the reduction with downward motion was about $61 \%$. Thus, the illusion reduction in both upward and downward motion conditions was nearly the same.

\section{EXPERIMENT 3}

This experiment was planned to measure how subjective alignment of the test lines changed with the location of the obliques.

\section{Method}

With a stationary Poggendorff figure, alignment errors were measured for three locations of the test lines: (1) the upper part, (2) the center part, and (3) the lower part of the ventrical parallels. In the case of (1), the length of $G C$ was $5 \mathrm{~cm}$. In the case of (2), the middle point of $\mathrm{BC}$ was $1.5 \mathrm{~cm}$ above the center of the picture. In the case of (3), the length of $F B$ was $5 \mathrm{~cm}$.

Each subject completed four conditions: a control condition, in which test lines moved at the rate of $21.2 \mathrm{deg}$ of visual angle per second, and three experimental conditions, in which test lines were stationary but in three different locations.

The order of the four conditions was determined randomly. Eight volunteers were selected randomly from among 88 subjects.

\section{Results}

Mean values of alignment error were 3.0, 7.0, 6.7, and $7.0 \mathrm{~mm}$, respectively, for control, (a), (b), and (c). Standard deviations were 1.5, 1.6, 1.6, and $2.1 \mathrm{~mm}$, respectively. Differences between control and (a), between control and (b), and between control and (c) were significant $[\mathrm{t}(7)=5.23, \mathrm{p}<.001$; $\mathrm{t}(7)=4.74, \mathrm{p}<.005 ; \mathrm{t}(7)=4.35, \mathrm{p}<.005$, respectively]. Differences between (a) and (b), between (b) and (c), and between (c) and (a) were not significant $[\mathrm{t}(\mathrm{ab})=.36, \mathrm{p}>.7 ; \mathrm{t}(\mathrm{bc})=.30, \mathrm{p}>.7 ; \mathrm{t}(\mathrm{ca})=0, \mathrm{p}=$ 1.0]. (See Table 2.)

Thus, not only were the results of Experiments 1 and 2 confirmed, but also it was shown that the location of the test lines was not a main cause of the reduction of the Poggendorff illusion.

\section{EXPERIMENT 4}

This experiment was planned to measure any shrinkage of space in the vertical dimension due to vertical motion of the stimulus and the vertical tracking eye movement of the subject.

\section{Method}

The stimulus was a $4 \times 4 \mathrm{~cm}$ square with a small fixation point in the center. In one condition, the whole stimulus (square and fixation point) moved vertically. In the other condition, the stimulus was stationary. When the stimulus moved vertically at a rate of $21.2 \mathrm{deg} / \mathrm{sec}$, the subjects were requested to track the point. In both conditions, the task of the subjects was to make the figure appear square. The length of the vertical sides of the square was changed, as in Experiments 2 and 3, by the double, randomly interleaved technique. The order of the two conditions was random.

Eight volunteers served in this experiment. Five of them had served in Experiment 2 and three of them in Experiment 3.

Table 2

Location of Oblique Lines and Illusion Magnitude

\begin{tabular}{|c|c|c|c|c|}
\hline & \multicolumn{2}{|c|}{$\begin{array}{l}\text { Illusion Magnitude } \\
\text { (in Millimeters) }\end{array}$} & \multirow[b]{2}{*}{$t(7)$} & \multirow[b]{2}{*}{$\mathbf{p}$} \\
\hline & Mean & SD & & \\
\hline \multicolumn{5}{|c|}{ Stationary } \\
\hline UL & 7.0 & 1.5 & 5.23 & $<.001$ \\
\hline $\mathrm{CL}$ & 6.7 & 1.6 & 4.74 & $<.005$ \\
\hline $\bar{L} \mathbf{L}$ & 7.0 & 2.1 & 4.35 & $<.005$ \\
\hline Moving & 3.0 & 1.5 & & \\
\hline
\end{tabular}

Note $-U L=$ upper location; $C L=$ center location; $L L=$ lower location. Student $t$ value and significance level for each location are calculated for illusion magnitude in motion. 
Table 3

Display Time (in Milliseconds) and Illusion Magnitude (in Millimeters)

\begin{tabular}{rcccc}
\hline $\begin{array}{c}\text { Display } \\
\text { Time }\end{array}$ & \multicolumn{2}{c}{ Illusion Magnitude } & & \\
\cline { 3 - 5 } & Mean & SD & $\mathrm{t}(9)$ & $\mathrm{p}$ \\
\hline 8 & 8.7 & 3.0 & .323 & $>.7$ \\
64 & 8.5 & 3.2 & .464 & $>.6$ \\
128 & 8.7 & 3.0 & .323 & $>.7$ \\
256 & 9.3 & 3.3 & .151 & $>.9$ \\
512 & 9.8 & 2.4 & .646 & $>.5$ \\
2,048 & 9.1 & 2.2 & & \\
4,098 & 9.1 & 2.9 & .000 & $=1.0$ \\
\hline
\end{tabular}

Note-Student $t$ value and significance level are calculated for illusion magnitude in a display time of $2,048 \mathrm{msec}$.

\section{Results}

The mean value of adjustment error for the control condition was $-1.85 \mathrm{~mm}$ and the SD was $1.25 \mathrm{~mm}$. That for the experimental condition was $-1.88 \mathrm{~mm}$ and the SD was $1.24 \mathrm{~mm}$. There was no significant difference between them $[t(9)=.0049, p>.9]$. On this basis, it is concluded that shrinkage in the vertical dimension is probably not the main cause for the reduction of the dynamic Poggendorff illusion.

\section{EXPERIMENT 5}

This experiment was planned to determine whether the display time of the stimulus was a main cause for the reduction of the illusion magnitude.

\section{Method}

Alignment errors were measured at seven display times with a stationary display: (1) 8, (2) 64, (3) 128, (4) 256, (5) 512 , (6) 2,048 , and (7) 4,096 ms.

Each subject completed seven conditions corresponding to the seven display times, with the order of the seven conditions being determined randomly.

Ten volunteers were selected randomly from among 88 subjects.

\section{Results}

The mean values of alignment error for conditions $1-7$ were $8.7,8.5,8.7,9.3,9.8,9.1$, and $9.1 \mathrm{~mm}$, respectively, with SDs of 3.0, 3.2, 3.0, 3.3, 2.4, 2.2, and $2.9 \mathrm{~mm}$, respectively. The mean value of the sixth condition $(9.1 \mathrm{~mm})$, which was the control condition in Experiment 2, was not significantly larger than those of others. (See Table 3.) Thus, it can be concluded that display time was not a main cause for the reduction of the Poggendorff illusion.

\section{EXPERIMENT 6}

This experiment was planned to see exactly how the alignment error of the Poggendorff illusion changes with the velocity of the oblique lines.

\section{Method}

Alignment errors were measured at five velocities: 1.3, 2.7, $5.3,10.6$, and $21.2 \mathrm{deg}$ of visual angle per second. Each subject completed two conditions: a control condition, in which the oblique lines were stationary, and an experimental condition, in which the oblique lines moved at one of the five velocities. The order of the two conditions was determined randomly. Fifty volunteers were selected randomly from among the 88 subjects.

\section{Results}

The mean value of SD, the mean value of the control condition and $\mathrm{SD}$, the reduction magnitude and $\mathrm{SD}$, the reduction magnitude in percentage, and Student ratio and significance level for each velocity are shown in Table 4.

A significant reduction of illusion magnitude was observed even at the low velocity of 1.3, deg of visual angle per second. The reductions at 1.3, 2.7, 5.3, and $10.5 \mathrm{deg}$ of visual angle per second were $60 \%, 80 \%$, $80 \%$, and $90 \%$ of the one at $21.2 \mathrm{deg}$ of visual angle per second, respectively.

\section{DISCUSSION}

In the current experiments, the reduction in the magnitude of the Poggendorff illusion was measured under conditions in which the test figure moved vertically as subjects tracked it. The aim was to investigate whether or not the interaction between moving and stationary figures was of the same size as that between two stationary figures.

The main results were: (1) Some reduction of illusion magnitude was observed for all of the subjects (84) in these experiments. Significant reduction

Table 4

Change of Illusion Magnitude with Velocity

\begin{tabular}{|c|c|c|c|c|c|c|c|c|c|c|}
\hline \multirow[b]{2}{*}{ Velocity* } & \multicolumn{2}{|c|}{$\begin{array}{l}\text { Mean } 1 \text { (Moving) } \\
\text { (in Millimeters) }\end{array}$} & \multicolumn{2}{|c|}{$\begin{array}{l}\text { Mean } 2 \text { (Stationary) } \\
\text { (in Millimeters) }\end{array}$} & \multicolumn{2}{|c|}{$\begin{array}{c}\text { Reduction } 1 \\
\text { (in Millimeters) }\end{array}$} & \multicolumn{2}{|c|}{$\begin{array}{r}\text { Reduction } 2 \\
\text { (in Percent) }\end{array}$} & \multirow[b]{2}{*}{$t(9)$} & \multirow[b]{2}{*}{$\mathbf{p}$} \\
\hline & Mean & SD & Mean & SD & Mean & SD & Mean & SD & & \\
\hline 21.2 & 4.0 & 2.5 & 9.7 & 2.2 & 5.8 & 1.5 & 60 & 15 & 5.27 & $<.001$ \\
\hline 10.6 & 4.8 & 2.4 & 10.6 & 2.3 & 5.8 & 1.6 & 55 & 15 & 5.12 & $<.001$ \\
\hline 5.3 & 4.7 & 2.0 & 9.2 & 3.1 & 4.5 & 1.9 & 49 & 20 & 3.69 & $<.005$ \\
\hline 2.7 & 4.0 & 1.6 & 7.5 & 2.0 & 3.6 & 1.2 & 48 & 16 & 4.18 & $<.002$ \\
\hline 1.3 & 6.8 & 3.5 & 10.3 & 3.1 & 3.5 & 1.5 & 34 & 15 & 2.29 & $<.005$ \\
\hline
\end{tabular}

Note-Means 1 and 2 are the illusion magnitude in experimental (moving) and control (stationary) conditions, respectively. Reductions 1 and 2 are the reduction magnitudes in absolute difference and in percentage, respectively. The mean value for control conditions of five groups of subjects was $9.5 \mathrm{~mm}(S D=1.1) . \quad$ *In degrees per second. 
of illusion magnitude was obtained in all of the experiments. (2) The experiments seem to indicate that location of test lines, perceptual shrinkage of space in the vertical dimension, and effective display time were not main factors contributing to reduction in illusion magnitude. Instead, it seems that some reduction in interaction between test and inducing lines was the main factor of the reduction of illusion magnitude. (3) The reduction at a low velocity of $1.3 \mathrm{deg}$ of visual angle per second was about $60 \%$ of the reduction obtained with a high velocity of $21.2 \mathrm{deg}$ of visual angle per second. However, systematic investigation of velocity showed that the reduction in magnitude was almost constant over most of the range of velocities studied. (4) The reduction obtained with upward motion was nearly the same size as that with downward motion. (5) The interaction between the moving test figure and stationary inducing figure did not disappear completely at high velocity, but remained about $40 \%$.

It is possible that, in addition to velocity, the gap between the parallels also affects illusion reduction in this situation. The reduction in Experiment 1 (gap = $.7 \mathrm{deg}$ ) was about $50 \%$, and that in Experiments 2, 3, and $6(\mathrm{gap}=3.2 \mathrm{deg})$ was about $60 \%$. Some of this difference may derive from the fact that the velocity of test lines in the control condition of Experiment 1 was very slow, but not zero $(.2 \mathrm{deg} / \mathrm{sec})$. The reduction percentage of the smaller gap may be smaller.

An assessment of the reduction of $60 \%$ in the current experiment follows.

Girgus, Coren, Durant, and Porac (1975) concluded that initial illusion reduction derives from a reduction of noncognitive components (peripheral components) because the reduction in magnitude by prolonged viewing was nearly the same size as an illusion magnitude of dot form (cognitive components). They obtained a reduction of $35 \%(\mathrm{cog}-$ nitive components) using the full Mueller-Lyer illusion. Using a dot form of illusion, Coren (1970) obtained a reduction of $29 \%$ (noncognitive components) with the Mueller-Lyer illusion and a reduction of $34 \%$ (noncognitive components) with the Poggendorff illusion. Using the data of Coren's (1970) dot form and Goldstein and Weintraub's (1972) subjective contour form, Coren et al. (1978) reported a reduction in illusion magnitude of about $40 \%$ (noncognitive components) for the Poggendorff illusion. According to the interpretation of Coren et al. (1978) and Girgus et al. (1975), the reduction of $60 \%$ in the present experiments must be a reduction of noncognitive components. There exists a big difference between the current data and Coren's (1970) data and Coren et al.'s (1978) report. However, Wenderoth and Wade (Note 1), using the dot form of the Poggendorff illusion, obtained a reduction in magnitude of $67 \%$ (noncognitive components). Taken together, Girgus et al. (1975) and Wenderoth and Wade (Note 1), the reduction of $60 \%$ in the present experiments seems reasonable. The angle between the parallels and the obliques in the current study and Wenderoth et al.'s experiments was $45 \mathrm{deg}$, whereas in Coren's (1970) experiment, it was $30 \mathrm{deg}$. The reduction percentage may be changed due to this difference in angle.

What is the main cause of the reduced interaction between the test and inducing figures? The following outlines one possibility. (1) There exist sustained and transient channels (e.g., Ikeda \& Wright, 1974; Tolhurst, 1975). (2) There exist some neurons in the visual cortex of awake monkeys ( 7 of 18 cells) which process background-relative motion rather than retinarelative motion (Bridgeman, 1972). Consequently, the figure in motion and the stationary figure may be processed by separate channels, thus reducing any interaction between the test and inducing figures. Partly supporting this idea is evidence that the rising curve of the reduction was very steep with respect to velocity and the reduction in illusion magnitude was almost constant in the range of velocities studied. It has been suggested that any neural separation between test and inducing figures reduces illusions (Wenderoth, 1977). Having the test figure moving, as in the present experiments, may be acting to neurally separate the test and inducing figures and so reduce the illusion.

\section{REFERENCE NOTE}

1. Wenderoth, P., \& Wade, N. J. An investigation of the dot and line forms of the Müller-Lyer and Poggendorff illusions. Manuscript submitted for publication.

\section{REFERENCES}

Ansbacher, H. L. Distortion in the perception of real movement. Journal of Experimental Psychology, 1944, 34, 1-23.

Bridgeman, B. Visual receptive fields sensitive to absolute and relative motion during tracking. Science, 1972, 178, 1106-1108.

Cameron, E. H., \& Steele, W. M. The Poggendorff illusion. Psychological Review, 1905, 7(Monograph Supplement 29), 83111.

Cohen, R. L. On the relationship between phenomenal space and phenomenal velocity. Scandinavian Journal of Psychology, 1967, 8, 107-112.

Coren, S. Lateral inhibition and geometric illusions. Quarterly Journal of Experimental Psychology, 1970, 22, 274-278.

Coren, S., \& Girgus, J. S. Visual illusions. In R. Held, H. W. Leibowitz, \& H.-L. Teuber (Eds.), Handbook of sensory physiology (Vol. 8). Berlin: Springer, 1978.

Consweet, T. N. The staircase method in psychophysics. American Journal of Psychology, 1962, 75, 485-491.

Girgus, J. S., Coren, S., Durant, M., \& Porac, C. The assessment of components involved in illusion formation using a longterm decrement procedure. Perception \& Psychophysics, 1975, 18, 144-148.

Goldstein, M. B., \& Weintraub, D. J. The parallel-less 
Poggendorff: Virtual contours put the illusion down but not out. Perception \& Psychophysics, 1972, 11, 353-355.

IKEDA, H., \& Wright, M. J. Evidence for sustained and transient neurones in cat's visual cortex. Vision Research, 1974, 14, 133-136.

TolmuRST, D. J. Sustained and transient channels in human vision. Vision Research, 1975, 15, 1151-1155.

WENDEROTh, P. An analysis of the rod-and-frame illusion and its variants. In R. H. Day \& G. V. Stanley (Eds.), Studies in perception. Perth: University of Western Australia and Monash Press, 1977.

Wetherill, G. B., \& LevitT, H. Sequential estimation of points on a psychometric function. British Journal of Mathematical Statistical Psychology, 1965, 18, 1-10.

(Received for publication July 10, 1980; revision accepted September 3, 1980.) 